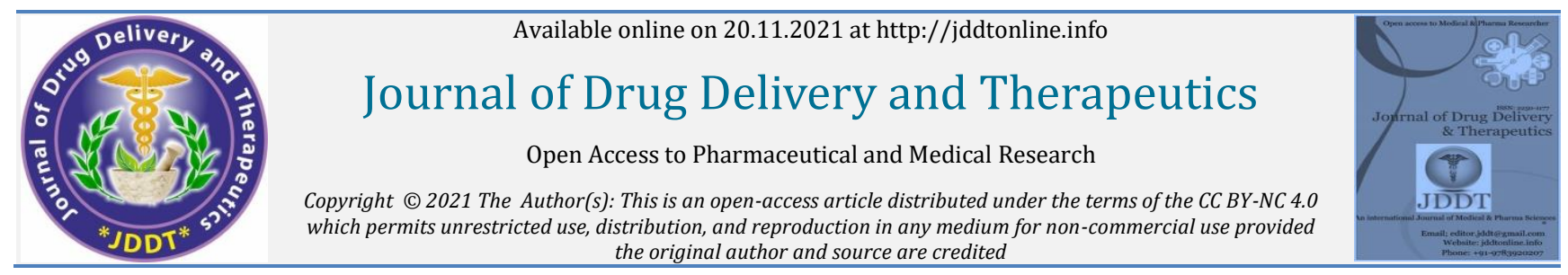
the original author and source are credited

Research Article

\title{
Subcronic Toxicity Effect of Ethanol Extract of Bitter Melon Fruit (Momordica charantia L.) on Kidney Function and Histopathological Changes in Wistar Rat
}

\author{
Welly Ratwita \\ Departement of Pharmacology Faculty of Medicine Jenderal Achmad Yani University, INDONESIA
}

Article Info:

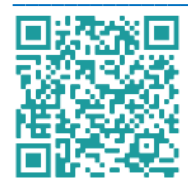

\section{Article History:}

Received 14 September 2021 Reviewed 28 October 2021 Accepted 11 November 2021

Published 20 November 2021

\section{Cite this article as:}

Ratwita W, Subcronic Toxicity Effect of Ethanol Extract of Bitter Melon Fruit (Momordica charantia L.) on Kidney Function and Histopathological Changes in Wistar Rat Journal of Drug Delivery and Therapeutics. 2021; 11(6):143-149

DOI: http://dx.doi.org/10.22270/jddt.v11i6.5168

*Address for Correspondence:

Welly Ratwita, Departement of Pharmacology Faculty of Medicine Jenderal Achmad Yani University, INDONESIA

\author{
Abstract
}

Bitter melon is a fruit that was famous for its bitter taste and contains chemical compounds that are proven to have effects such as antidiabetic, anti-inflammatory, antipyretic, and antioxidant. One of the prerequisites of a plant to be developed into a drug that is by testing the subchronic toxicity. This study goal to determine the presence of toxic effects that are not detected in the acute toxicity test. A total of 40 wistar rats were divided into group control and 3 treatment groups. Each group consisted of 5 male rats and female rats. Group 1 (control) is only given food (pellets) and drinking water. Group 2, 3 and 4 groups were given ethanol extract of bitter melon pulp (Momordica charantia L.) with multilevels doses 250 $\mathrm{mg} / \mathrm{kgbw}, 500 \mathrm{mg} / \mathrm{kgbw}$, and $1000 \mathrm{mg} / \mathrm{kgbw}$. The observations made for 28 days included the number of death animals, relative organ weight (ROW), ureum, creatinine levels and histopatological changes in kidney. There were no deaths in the entire group, decreasing ureum $(p=0,022)$, creatinine levels $(p=0,033)$ in male group. While in female group ureum decrease not significantly (0.878) and creatinine (0.845). There were no significant changes in ROW ( $p=0,370$ and $p=0,394)$, but there were changes in microscopic structure. In conclusion ethanol extract of bitter melon fruit (Momordica charantia L.) at a of 250 $\mathrm{mg} / \mathrm{kgbw}, 500 \mathrm{mg} / \mathrm{kgbw}$, and $1000 \mathrm{mg} / \mathrm{kgbw}$ does not showed any toxic effects on kidney function and relative organ weight. But microscopically, the administration of ethanol extract of bitter melon fruit caused a toxic effect on the kidney tubules in both male and female groups.

Keywords: Momordica charantia L., sub chronic toxicity, ureum, creatinine, histopathological change

\section{INTRODUCTION}

Indonesia is a country which has a very large biodiversity.1,2 This biodiversity were used by the Indonesian people to meet their needs, like food, shelter, clothing, fertilizer and even medicine. ${ }^{2}$ Traditional medicines has been used by the Indonesian people to overcome health problems. Traditional medicine are widely used by the community because it is easy to find, easy to obtain, can be mixed by yourself, and the price is relatively cheaper. ${ }^{1}$

Bitter melon (Momordica charantia L.) is a plant that grows in the tropics and famous for its bitter taste. Bitter melon contains alkaloid compounds, saponins, terpenoids, flavonoids, and tannins which are used as medicinal ingredients. ${ }^{3}$ Based on research conducted by Afifah et al. (2017) 96\% ethanol extract of bitter melon reduced blood sugar levels with an effective $150 \mathrm{mg} / \mathrm{kgbw}$ which is equivalent to metformin. ${ }^{4}$ Parawansah et al. (2016) proved $150 \mathrm{mg} / \mathrm{kgbw}$ of ethanol extract of bitter melon fruit was effective as an antipyretic and anti-inflammatory for
67.18\% inhibition. ${ }^{5}$ Bitter melon also contains curcubitacin which caused a bitter taste in bitter melon. Curcubitacin, which is classified as triterpenoid glycosides, has a steroid core structure that may act as an inhibitor of spermatogenesis reversibly.

A plant can be used as a traditional medicine if it meets the quality standards of the WHO including standards of quality, safety and efficacy. Toxicity testing is one of the prerequisites for a plant to be developed into a drug. ${ }^{6}$ Research on the effects of a plant has been widely studied, however, toxicity test has not been widely studied, so it needs to be further investigated. Toxicity is defined as the ability of a chemical substance to cause damage to organisms either when used or when in the environment. The toxicity test of a compound is divided into two groups, general and specific toxicity tests. Common toxicity tests include acute, subchronic, and chronic toxicity testing. 6

The results of the acute toxicity test on bitter melon carried out by Safitri (2015) showed that there were no deaths of mice until day 14, there was no effect of giving 
the ethanol extract of bitter melon fruit on body weight, and there was no significant change in relative organ weight. This toxicity test needs to be continued to the subchronic toxicity test because the bitter melon fruit is used repeatedly for a relatively long time, so it is necessary to carry out a subchronic toxicity test to determine the effect of using bitter melon fruit if used for a long time.

The subchronic toxicity test is one of the tests to detect toxic effects that arise after repeated doses of test preparations given orally to test animals every day or at least 5 days in 1 week for 28 days. During the time that the test preparation is administered, the animal should be observed daily for any toxic symptoms. All animals that are still alive, at the end of the test preparation period, blood is drawn for biochemical examination and an autopsy is performed to weigh the relative organs. ${ }^{6}$

One of the observation parameters for the toxicity test of a drug is the biochemical examination of the kidney, because the kidney is the main organ that has specific toxicity and its unique function in filtration, metabolism and excretion. The kidneys excrete solutes and remove metabolic products so that substances that are not useful for the body will be carried to the kidneys in large quantities. One way to find out whether kidney function is still good is by measured the ureum and creatinine levels. ${ }^{7}$

\section{MATERIALS AND METHODS}

\section{Plant material}

Fresh Bitter melon or Momordica charantia L. was collected from Cipatat, West Java, Indonesia. It was harvested at 2 months old, and was identified and characterized in Sekolah Ilmu dan Teknologi Hayati, Institut Teknologi Bandung, Indonesia.

\section{Bitter melon extract preparation}

The pulp of the bitter melon washed and drained. The clean bitter melon pulp were sliced, then dehydrated in a dehydrator oven for $12 \mathrm{hrs}$ before milled by a machine to get the powder of bitter melon pulp. The powder of bitter melon pulp macerated with $96 \%$ ethanol until submerged. The vessel were tightly closed and protected from light for 1 day while repeatedly stirring. The macerate is placed in a porcelain dish, while additional ethanol were added to the remaining filtrate. Maceration is carried out 3 times. The filtrate being evaporated in a water bath until a thick extract is obtained.

\section{Experimental animal}

Normal both male and female Wistar rats were used for sub chronic toxicity study. The animals were 6-8 weeks old, weighting 150-200 g and were stabilized for seven days prior to the experiments. They were acclimatized at room temperature, with $12 \mathrm{~h}$ light and $12 \mathrm{~h}$ dark cycle, as well as free access to a standard pellet diet and water ad libitum. During acclimatization, the rats were randomized into experimental and control groups. All experimental procedures were in compliance with the Guide for the Care and Use of Laboratory Animals and approved by the local animal care committee, The Health Research Ethic Committee of Faculty of Medicine Universitas Padjajaran Bandung-Indonesia, with ethical approval no 03/UN6.KEP/EC/2020.

\section{Sub chronic toxicity study}

Sub chronic toxicity study was performed according to the Organization of Economic Co-operation and Development
(OECD) guideline. ${ }^{8}$ The animals were randomly divided as follows, Group 1 (control) and Group 2 treated with ethanol extract of bitter melon (250 mg/kg bw), Group $3(500 \mathrm{mg} / \mathrm{kg} \mathrm{bw})$ and Group $4(1000 \mathrm{mg} / \mathrm{kg} \mathrm{bw})$ respectively. Each group contained 5 animals/sex/group. The test preparation was given orally every day with a single dose. ${ }^{9}$ At the end of the 28-day treatment period, all animal necropsied. All animals were fasted overnight prior to necropsy and euthanized by carbon dioxide inhalation.10 Relative organ weights, ureum, creatinine, histopathological changes were determined.

\section{Organ Weight}

Weighting was carried out at the beginning and at the end of the treatment period, so the weight could be monitored.

\section{Histopathology study}

First step in histopathology preparation was dehydration, which is useful for removing water from tissues due to tissue fixation that has been carried out in formalin solution. Dehydration was done by put the tissue in $10 \%$ formalin, then transferred to a beaker containing $70 \%$ alcohol in an incubator at $60^{\circ} \mathrm{C}$ for $3 / 4$ hours, then the tissue is transferred to a beaker containing $80 \%$ alcohol in a beaker. Incubator at $60^{\circ} \mathrm{C}$ for $3 / 4$ hours then the tissue was transferred to a beaker containing $95 \%$ alcohol in an incubator at $60^{\circ} \mathrm{C}$ for $1.5 \mathrm{~h}$. After that, the tissue was transferred to a beaker containing $100 \%$ alcohol in an incubator at $60^{\circ} \mathrm{C}$ for 2 h. ${ }^{11}$

After being dehydrated, the tissue being dehydrated with a lot of alcohol to replace water. This will cause paraffin wax in the infiltration process which is insoluble in alcohol; the entry process will be hampered. Paraffin wax infiltration process may take place with the help of xylol as an intermediary for paraffin wax infiltration. The xylol solution was given for 30 minutes at $38^{\circ} \mathrm{C}$, the xylol solution became transparent or clear and flammable. Paraffin wax infiltration is the infiltration of paraffin wax into the tissue, causing the tissue to harden due to infiltration at room temperature. Paraffin wax can maintain the function of cells and ultrastructural components during the cutting process.

The tissue containing paraffin wax after the infiltration process was planted in the base mold, then hot liquid paraffin wax similar to the infiltration process is poured into small boxes so as to form a paraffin block containing the tissue inside and its position is adjusted to facilitate the cutting process. The tissue was sliced by means of a paraffin block containing the tissue was sliced repeatedly using a microtome with a thickness of 4 micrometers.

The staining used in this study was Hematoxylin-eosin. The tissue that has been implanted in paraffin then cut using a microtome, deparaffinized using xylol to remove the paraffin. Furthermore, the rehydration process using alcohol lasted for approximately 3 minutes followed by a staining process using hematoxylin for 15 minutes and then washed with water. After washing, the differentiation process was carried out using $1 \%$ alcoholic acid for 5-10 seconds and washed again for a blueing process using lithium carbonate so that the blue color in the cell nucleus looked clearer. Furthermore, the dehydration process using alcohol is carried out so that the water contained in the tissue can be lost, and continued with the clearing process using xylol solution. Furthermore, the preparation was placed on an object glass and covered with a cover glass. Furthermore, the rats that had been treated and observed were then destroyed by incineration using an 
incinerator.

After the Hematoxylin-Eosin staining process of the kidney organs completed, microscopic observations were then carried out using a light microscope with a 400 times magnification lens on the microscope preparation. Observations were made on the renal cortex, namely the proximal tubule. This is because the character of the tubules has a weak and easily leaky epithelium and because damage to the kidneys that often occurs and is easily observed is damage to the renal tubules. ${ }^{11}$

Each preparation was observed at five different points of view, in each field of view the changes that occurred were observed. Renal proximal tubular damage was scored $0=$ normal, 1 = inflammatory cell infiltration, 2 = tubular epithelial cell edema, $3=$ necrosis). The assessment of the degree of kidney damage is taken from the highest damage that can be found in 1 field of view. ${ }^{\mathbf{2}}$ Inflammatory cell infiltration is the infiltration of cells or the entry of inflammatory cells from outside the tissue. of proximal tubular edema is an enlarged cell size and pale cytoplasm accompanied by loss of the proximal tubular lumen or brush border. ${ }^{12}$ Characteristics of necrosis of the proximal tubular epithelium are nuclear changes that lose chromatin appearance, become wrinkled, no longer vascular, the nucleus is denser, dark in color (pycnosis), the nucleus is divided into fragments, torn (cariolysis), the nucleus is no longer colorless or pale (caryolysis).

\section{RESULTS AND DISCUSSION}

The results of the observation of the ethanol extract of bitter melon fruit showed that there was no effect of the extract on the mortality of experimental animals. Body weight was still within normal limits, relative organ weights were not changed statistically significant, and the group with the lowest showed that the death of female rats was not a toxic effect. 6

\section{Effect of Ethanol Extract of Bitter Melon Fruit on Body Weight}

The body weight of all rats were continued to increase. The weight of the control group was greater than the group given the ethanol extract of bitter melon fruit, this was because the bitter melon contained tannin compounds. Tannin compounds have the potential to act as thermogenesis so that they can cause fat burning in the body which causes weight loss. Bitter melon can reduce the weight of overweight rats through the mechanism of increasing adenosine 5 monophosphate kinase (AMPK) activity. AMPK is an enzyme that plays a role in increasing the oxidation of fatty acids. This increase in the oxidation of these fatty acids ultimately leads to weight loss. ${ }^{\mathbf{1 3}}$

Table 1: The average body weight of rats before and after giving ethanol extract of bitter melon fruit

\begin{tabular}{|c|c|c|c|c|c|}
\hline & & \multicolumn{3}{|c|}{ Average Weight } & \multirow[b]{2}{*}{$p$} \\
\hline \multicolumn{2}{|c|}{ Group } & befon tro tm & & $\Delta$ & \\
\hline \multirow{4}{*}{ Male } & 1 & $139.60 \pm 4.72$ & $195.40 \pm 13.46$ & $55.80 \pm 10.25$ & \multirow{4}{*}{$0.016^{*}$} \\
\hline & 2 & $149.40 \pm 10.47$ & $184.80 \pm 22.80$ & $35.40 \pm 18.29$ & \\
\hline & 3 & $154.80 \pm 7.98$ & $185.00 \pm 6.36$ & $30.20 \pm 0.38$ & \\
\hline & 4 & $149.60 \pm 10.16$ & $177.60 \pm 13.66$ & $28.00 \pm 13.43$ & \\
\hline \multirow[t]{4}{*}{ Female } & 1 & $148.40 \pm 12.72$ & $195.00 \pm 12.70$ & $46.60 \pm 6.06$ & \multirow[t]{4}{*}{$0.001^{*}$} \\
\hline & 2 & $143.40 \pm 10.52$ & $164.20 \pm 11.38$ & $20.80 \pm 7.25$ & \\
\hline & 3 & $139.00 \pm 3.24$ & $153.00 \pm 13.43$ & $14.00 \pm 15.37$ & \\
\hline & 4 & $140.80 \pm 3.63$ & $160.40 \pm 10.73$ & $19.60 \pm 11.23$ & \\
\hline
\end{tabular}

\footnotetext{
$*: p \leq 0,05$ (significantly different with anova test), $\Delta$ difference weight between post-pre treatment, Group 1: Control, without treatment, Group 2: bitter melon extract $250 \mathrm{mg} / \mathrm{kgbw}$, Group 3: bitter melon extract $500 \mathrm{mg} / \mathrm{kgbw}$. Group 4: bitter melon extract 1000 mg/kgbw, respectively.
}

The One Way Anova test results in Table 1 show the value of $p=0.016$ in male rats and $p=0.001$ in female. Therefore, it can be concluded that there are significant differences in body weight of rats. In order to find out which groups had significant differences, the Tukey Post Hoc Test was performed. 
Table 2: Body weight in post hoc Tukey

\begin{tabular}{|c|c|c|c|c|c|}
\hline \multirow{2}{*}{ Group } & & \multicolumn{4}{|c|}{$\mathrm{p}$} \\
\hline & & 1 & 2 & 3 & 4 \\
\hline \multirow{4}{*}{ Male } & 1 & & 0.108 & 0.033 & $0.020^{*}$ \\
\hline & 2 & 0.108 & & 0.923 & 0.812 \\
\hline & 3 & $0.033^{*}$ & 0.923 & 0.993 & \\
\hline & 4 & $0.020^{*}$ & 0.812 & 0.993 & \\
\hline \multirow{4}{*}{ Female } & 1 & & $0.007^{*}$ & $0.001 *$ & $0.005^{*}$ \\
\hline & 2 & $0.007^{*}$ & & 0.745 & 0.998 \\
\hline & 3 & $0.001 *$ & 0.745 & & 0.838 \\
\hline & 4 & $0.005^{*}$ & 0.998 & 0.838 & \\
\hline
\end{tabular}

*: $p \leq 0,05$ (significantly different with anova test), Group 1: Control, without treatment, Group 2: bitter melon extract 250 mg/kgbw, Group 3: bitter melon extract $500 \mathrm{mg} / \mathrm{kgbw}$. Group 4: Bitter melons extract $1000 \mathrm{mg} / \mathrm{kgbw}$, respectively.

This significant difference indicates the effect of giving the extract on changes in body weight of rats. Bitter melon contains many chemical compounds, one of which is tannins which play a role in weight loss. ${ }^{13}$

\section{Effect of Ethanol Extract of Bitter Melon Fruit on Ureum and Creatinine}

Blood sampling was initiated under anesthesia using $\mathrm{CO}_{2}$ by inhalation at a concentration of $30 \%$ were taken slowly from the ophthalmic veins to check for ureum and creatinine. Data regarding ureum and creatinine examination in all groups were normally distributed and homogeneous ( $p>0.05)$. Furthermore, the statistical test used is the one way ANOVA test. The results of the one way ANOVA test can be seen in Table 3 .

Table 3: Ureum and creatinine level

\begin{tabular}{clrcccc}
\hline \multirow{2}{*}{ Sex } & & \multicolumn{4}{c}{ Average of Ureum and Creatinine $\pm S D$} & \multirow{2}{*}{$p$} \\
\cline { 3 - 6 } & & \multicolumn{1}{c}{1} & 2 & 3 & 4 \\
\hline \multirow{2}{*}{ Male } & Ureum & $59.28 \pm 11.42$ & $47.20 \pm 5.44$ & $46.88 \pm 4.21$ & $42.47 \pm 8.20$ & $0.022^{*}$ \\
& Creatinine & $0.56 \pm 0.05$ & $0.39 \pm 0.04$ & $0.53 \pm 0.16$ & $0.26 \pm 0.13$ & $0.003^{*}$ \\
\multirow{2}{*}{ Female } & Ureum & $37.75 \pm 21.48$ & $31.26 \pm 18.26$ & $30.06 \pm 17.83$ & $28.89 \pm 16.86$ & 0.878 \\
& Creatinine & $0.45 \pm 0.25$ & $0.33 \pm 0.19$ & $0.35 \pm 0.21$ & $0.39 \pm 0.22$ & 0.845
\end{tabular}

*: $p \leq 0,05$ (significantly different with anova test), Group 1: Control, without treatment, Group 2: bitter melon extract 250 mg/kgbw, Group 3: bitter melon extract $500 \mathrm{mg} / \mathrm{kgbw}$. Group 4: bitter melon extract $1000 \mathrm{mg} / \mathrm{kgb}$, respectively .

Control male rat group had higher ureum and creatinine level than group 2,3, and 4 . It were significantly different $(p=0.022$ and $p=0.003)$. It means that there was an effect of giving the ethanol extract of bitter melon fruit at a of $250 \mathrm{mg} / \mathrm{kgbw}, 500 \mathrm{mg} / \mathrm{kgbw}$, and $1000 \mathrm{mg} / \mathrm{kgbw}$ to kidney function. In contrast to male rats, there were no significant differences in female rats both for ureum and creatinine $(\mathrm{p}>0.05)$. To find out more about the comparison between the control group and the three doses in male rats, further tests were carried out using the Post Hoc test.

The results of the post hoc test showed that there is a significant difference $(\mathrm{p}=0.018)$ in ureum levels in the group 4 compared to control (group 1) male, and the creatinine level shows that there was significant differences between group 4 compared to control (group 1) male $(p=0.005)$, and group 4 compared to group $3(p=$ 0.009).

The ureum and creatinine levels in the group given the ethanol extract of bitter melon fruit in both male and female rats were lower than the control group, this is because the bitter melon plant contains antioxidants that play an important role in the body. The antioxidants contained in bitter melon, namely vitamin $\mathrm{C}$ and flavonoids. The mechanism of action of vitamin $\mathrm{C}$ as an antioxidant, namely acts as an electron donor so that free radicals will be suppressed and prevent further chain reactions, while the antioxidant mechanism of flavonoids, namely capturing and destroying free radicals and limiting the formation of free radicals so that lipid peroxidation does not occur which can damage kidney cells.

Free radicals are one of the products of chemical reactions in the body which are highly reactive and contain unpaired electrons in outer orbitals so they are unstable. These free radicals can cause damage to kidney cells, both glomerular and tubular cells and target the damage, namely lipids by changing their structure and function. The permeability of the cell membrane will increase, which is followed by a massive influx of calcium and cell death. This damage can be prevented by the presence of antioxidants that provide a protective effect in the kidneys to fight the damage 
process caused by free radicals.

\section{Histopathological Changes}

Microscopic images in the male control group found more normal proximal tubules as in Figure A, normal proximal tubules were characterized by cuboidal epithelium with intact nuclei and cytoplasm accompanied by intact lumen.15 In the treatment group 1 male, abnormalities in the form of cell infiltration were found. inflammation to cell necrosis. Infiltration of inflammatory cells can be seen by finding inflammatory cells with a purplish red color. ${ }^{\mathbf{1 6}}$
Proximal tubular edema also occurs in several fields of view in male treatment group 1. It can be seen as in Figure 1.C with the characteristics of enlarged cell size, pale cytoplasm accompanied by loss of the proximal tubular lumen image.12 Cell death or necrosis can also be found in the treatment group 1 male, we can see cell necrosis as in Figure 1.D with the characteristics of the nucleus losing chromatin image, wrinkles, darker color, tearing or also can be found pale nuclei.17. Treatment group 2 and 3 males had more tubular edema and necrosis. An overview of the comparison of normal proximal tubules with damage that occurs can be seen in Figure 1.

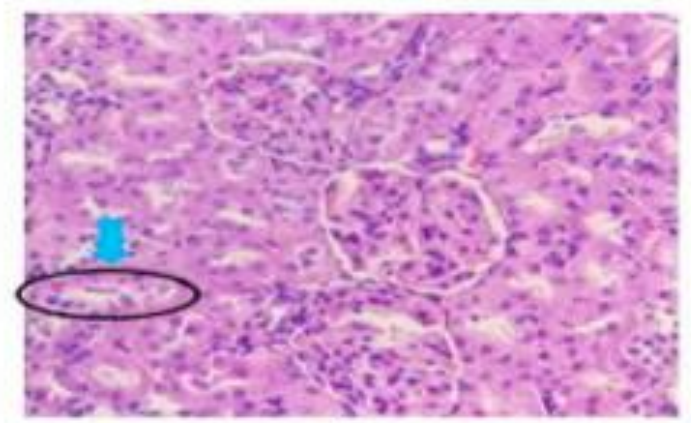

A

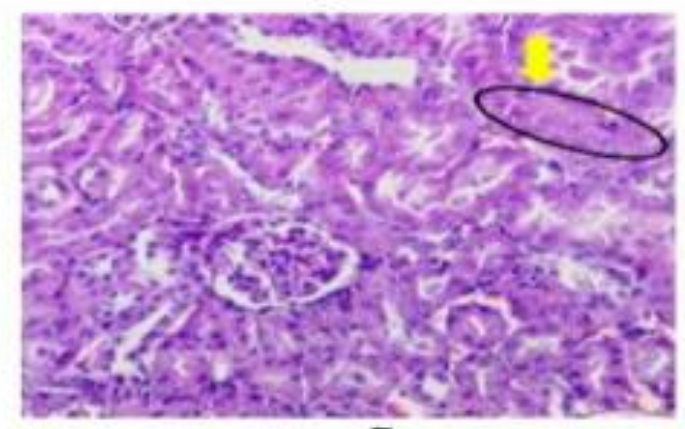

C

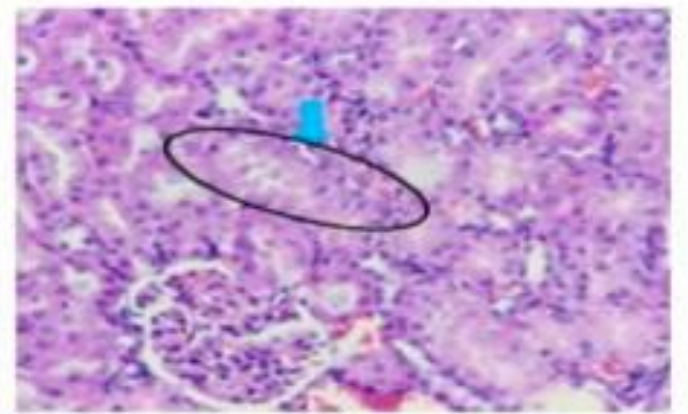

B

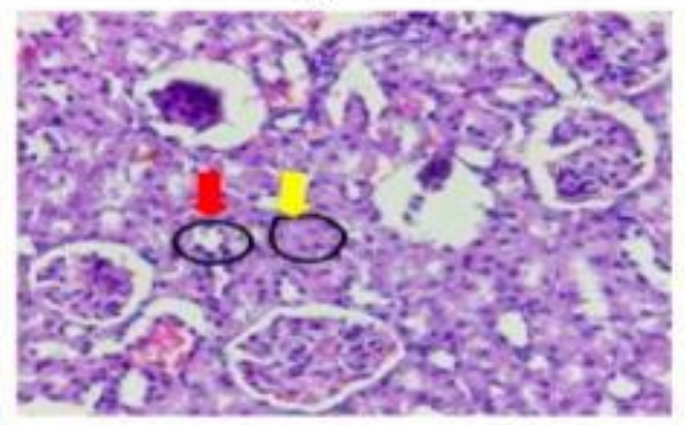

$\mathbf{D}$

Figure 1: Histopathological changes in male group

Note: The image above is the result of a 400x magnification microscopic image with Hematoxylin Eosin staining. Figure A is group 1 (control), B is group 2 (250 mg/kgbw), C is group $3(500 \mathrm{mg} / \mathrm{kgbw})$ and image D is group 4 (1000 mg/kgbw).

Normal tubule (blue arrow), tubular edema (yellow arrow), and necrosis (red arrow).

The histopathological changes in the female control group was the same as the male control group, it was found that many proximal tubules were normal as shown in Figure $2 \mathrm{~A}$. In the treatment group 1 female had many proximal tubules that were normal to those with proximal tubular edema. In treatment groups 2 and 3, there were many abnormalities ranging from inflammatory cell infiltration to proximal tubular cell necrosis. The higher doses, the more cell necrosis findings. We can see the histopathological changes in Figure 2.

Tubular damage that occurred in the group given the ethanol extract of bitter melon fruit in both male and female rats was greater than the control group; this was because the bitter melon plant contained tannin compounds. Tannins when reacting with electrolytes will form complex compounds that are insoluble in the digestive system, causing oxygen deficiency. The cells in the living body depend on a continuous supply of oxygen, without oxygen maintenance activities and cell synthesis will stop, if it takes a long time the cells can no longer carry out metabolism and eventually cause cell death. Giving large amounts of tannins can cause kidney irritation and other disorders. The ethanol extract of bitter melon leaves also contains saponins, saponins can cause kidney problems and liver damage. Saponins can also cause loss regulation of ionic balance and osmotic pressure as well as physiological dysfunction resulting in death. 18 


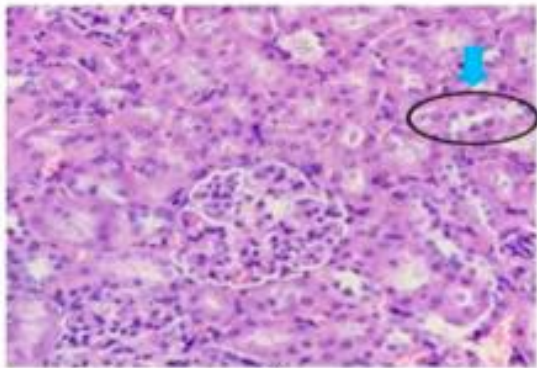

$\mathbf{A}$

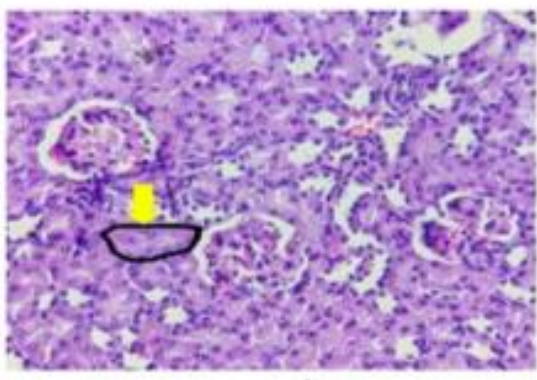

C

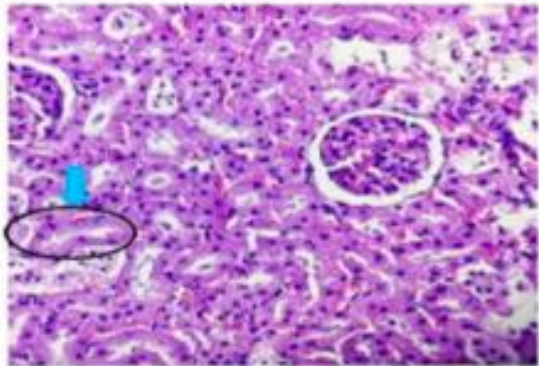

B

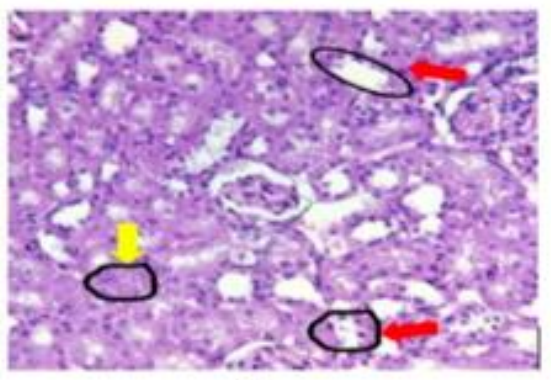

D

Figure 2: Histopathological changes in male group

Note :The image above is the result of a 400x magnification microscopic image with Hematoxylin Eosin staining. Figure A is group 1 (control), B is group 2 (250 mg/kgbw), C is group 3 (500 mg/kgbw) and image D is group 4 (1000 mg/kgbw).

Normal tubule (blue arrow), tubular edema (yellow arrow), and necrosis (red arrow)

The results of the proximal tubule examination first performed a normality test using the Shapiro Wilk test, to determine whether the distribution is normal or not. Data regarding the examination of the proximal tubule of all groups in normal and homogeneous distribution ( $\mathrm{p}>0.05)$. Furthermore, the statistical test used is the one way ANOVA parametric test. The results can be seen in Table 4 .

Table 4: Proximal tubule damage

\begin{tabular}{lcccc}
\hline \multirow{2}{*}{ Group } & \multicolumn{2}{c}{ Mean \pm SD } & T2 & T3 \\
\cline { 2 - 5 } & $0.20 \pm 0.20$ & $0.56 \pm 0.29$ & $0.56 \pm 0.29$ & $1.04 \pm 0.20$ \\
\hline Male & T1 & $0.84 \pm 0.21$ & $1.08 \pm 0.22$ \\
\hline$*: p \leq 0,05$ (significantly different with anova test), Group 1: Control, without treatment, Group 2: bitter melon extract 250 mo/kgbw, Group
\end{tabular}

3: bitter melon extract $500 \mathrm{mg} / \mathrm{kgbw}$. Group 4: bitter melon extract $1000 \mathrm{mg} / \mathrm{kgb}$, respectively .

Based on Table 4, both male and female rats had an average value of tubular damage that was less visible in the control group than in the treatment groups. The results of the examination on male and female rats were found to be statistically significant because $p=0.004$ and $p=0.000$ meaning that there was an effect on the ethanol extract of bitter melon fruit using a of $250 \mathrm{mg} / \mathrm{kgbw}, 500 \mathrm{mg} / \mathrm{kgbw}$, and $1000 \mathrm{mg} / \mathrm{kgbw}$ of renal tubule seen from examination of its microscopic structure. The comparison between the control group and the three doses in male and female rats had a significant difference, so that further tests were carried out using the Post Hoc test. It can be seen that there is a significant difference in tubular damage in the group 4 compared to the control group $(p=0.003)$ and the group 4 compared to group 3 ( $p=0.034$ ), and there is a significant difference in the results of the analysis of rat tubular damage.

Females in the group 3 compared to control group ( $p=$ 0.003) and control group compared to the group $4(\mathrm{p}=$ ISSN: 2250-1177
$0.000)$. Differences in tubular damage also occurred in group 2 compared to group $3(\mathrm{p}=0.041)$ and group $4(\mathrm{p}=$ 0.02 ). This significant difference in the level of tubular damage indicated that the fruit extract bitter melon is toxic, because there was damage to the tubules in both the male and female groups given the ethanol extract of bitter melon fruit. Based on the results of this study, it was found that there was damage to the kidney tubules in both male and female rats given the ethanol extract of bitter melon leaves. This indicates that the ethanol extract of bitter melon fruit is toxic to the microscopic structure of the kidneys, in this study the tubules.

\section{CONCLUSION}

Ethanol extract of bitter melon fruit (Momordica charantia L.) at a of $250 \mathrm{mg} / \mathrm{kgbw}, 500 \mathrm{mg} / \mathrm{kgbw}$, and 1000 $\mathrm{mg} / \mathrm{kgbw}$ does not showed any toxic effects on kidney function and relative organ weight. But microscopically, the administration of ethanol extract of bitter melon flesh 
caused a toxic effect on the kidney tubules in both male and female groups.

\section{ACKNOWLEDGEMENT}

This work was supported by Jenderal Achmad Yani University, Indonesia.

\section{REFFERENCES}

1. Ministry of Trade of the Republic of Indonesia. Traditional herbal medicine. Export News 2014; 005:1-20.

2 Sutoyo. Indonesia's biodiversity. Science World 2010; 10:101106.

3. Jia S, Shen M, Zhang F, Xie J. Recent advances in Momordica charantia: Functional components and biological activities. International Journal of Molecular Sciences 2017; 18:2555. https://doi.org/10.3390/ijms18122555

4 Afifah UN. Antidiabetic activity test of $96 \%$ ethanol extract of bitter melon (Momordica charantia L.) against alloxaninduced wistar male rats. Surakarta: Faculty of Pharmacy, Muhammadiyah Surakarta University. 2017.

5 Parawansah, Wahyuni, Mahmudah Z. Test of antipyretic and anti-inflammatory effects of ethanol extract of bitter melon (Momordica charantia L.) on male mice. Kendari: Faculty of pharmacy, Universitas Halu Oleo. 2016.

6 Regulation of the Head of the Food and Drug Supervisory Agency of the Republic of Indonesia No 7. Guidelines for in vivo non-clinical toxicity tests. PerKBPOM. Jakarta. 2014.

7. Guyton AC, Hall JE. Guyton and Hall. Nedical physiology textbook. Ed 12. Singapore: Elsevier; 2011. p 325-45.

8 Food and Drug Supervisory Agency. Guidelines for In Vivo Nonclinical Toxicity Testing. 2014(June): p 1-2.

9. OECD Guidelines for the Testing of Chemicals: Acute Oral Toxicity-Fixed Dose Procedure, OECD/OCDE 420. Adopted: 17th December 2001

10. American Veterinary Medical Association. Guidelines for the euthanasia of animals: 2013 Edition. AVMA. 2013.

11. Medical Laboratory Technology Teaching Materials. 2017. Cytohistotechnology. Jakarta: Ministry of Health of the Republic of Indonesia. p:139-58.

12 Siagian M, Jusuf AA, Handini M. Effect of monosodium glutamate exposure on rat kidney function and histology and its changes after cessation of exposure. Journal Indonesia Medical Association. 2014; 64(7).

13. Priyanto. Toxic effect of a substance. In: Sunaryo H, editor. Toxicology (Mechanisms, Antidote Therapy, and Risk Assessment). Depok. Leskonfi. 2009. hal. 37-47.

14 Anilakumar KR, Kumar GP, Ilaiyaraja N. Nutritional, pharmacological and medicinal properties of Momordica charantia L. Int. J. Nutr. Food Sci. 2015; 4(1):75-83 https://doi.org/10.11648/j.ijnfs.20150401.21

15. Praptiwi, Nurkanto A, Wulansari D, Agusta A. Acute oral toxicity of two compounds bisantraquinone (+)-2,2'epicytocycrine $A$ and (+)-1,1'-bislunatine. Biology News. 2015; 14(1):11-18.

16 Sugihartini N, Fajri NA. Histopathological Description of Liver and Kidneys of Balb/c Mice after Administration of Green Tea Extract Cream (Camellia sinensis L.). Yogyakarta: Faculty of Pharmacy, Ahmad Dahlan University. 2016.

17. Almunawati, Budiman H, Aliza D. Histopathology of the kidneys of white rats (Rattus norvegicus) injected with formalin. Banda Aceh: Faculty of Veterinary Medicine, Syiah Kuala University. 2017.

18 Nasikha FI, Subchronic Toxicity Test of Ethanol Extract of Matoa Leaves (Pometia Pinnata) With Bun, Creatinine and Kidney Histopathology Parameters in Wistar Strain Rats. Surakarta: Faculty of Pharmacy, Setia Budi University. 2018. 